\title{
Solvent-Induced On/Off Switching of Intramolecular Electron Transfer in a Cyanide-Bridged Trigonal Bipyramidal Complex ${ }^{\dagger}$
}

Rong-Jia Wei, ${ }^{a}$ Ryohei Nakahara, ${ }^{a}$ Jamie M. Cameron, ${ }^{a}$ Graham N. Newton, ${ }^{a, b}$ Takuya Shiga, ${ }^{a}$ Hajime Sagayama, ${ }^{c}$ Reiji Kumai, ${ }^{c}$ Youichi Murakami, ${ }^{\mathrm{c}}$ and Hiroki Oshio ${ }^{* a}$

a. Graduate School of Pure and Applied Sciences, University of Tsukuba, Tsukuba 305-8571, Japan. E-mail: oshio@chem.tsukuba.ac.jp; fax: +81-29-853-4238; tel: +81-29-853-4238

School of Chemistry, The University of Nottingham, University Park, Nottingham, NG7 2RD, UK

Photon Factory and Condensed Matter Research Center, Institute of Materials Structure Science, High

Energy Accelerator Research Organization (KEK), Tsukuba 305-0801, Japan

tElectronic Supplementary Information (ESI) available: Experimental details, Mössbauer parameters Synchrotron powder

XRD pattern, and additional structural figures. CCDC $1494652-1494654$ for 1 (100 K), 1 (300 K) and $1^{\text {de }}$ (100K), respectively

A cyanide-bridged $\left[\mathrm{Co}_{3} \mathrm{Fe}_{2}\right]$ cluster with trigonal bipyramidal geometry shows solvent-driven reversible on/off switching of its thermally induced electron-transfer-coupled spin transition (ETCST) behaviour.

Due to the favourable electronic exchange interactions offered by cyanide ions, cyanide-bridged mixed valence [CoFe] systems have been reported to show intramolecular electron-transfer behavior between neighboring metal ions, reversibly converting the diamagnetic [Co'"'Ls-Fe" $\llcorner s]$ state to the paramagnetic [ $\mathrm{CO}^{\prime \prime} \mathrm{HS}^{-}-\mathrm{Fe}{ }^{\prime \prime \prime}$ 'ss] state (LS = low spin and HS = high spin). ${ }^{1}$ This so-called electron-transfercoupled spin transition (ETCST) phenomenon can be triggered by temperature variation or light irradiation, allowing potential application in future technologies such as next-generation information storage materials, sensors and nanoscale switching devices. ${ }^{2}$ ETCST behaviour was first reported by Hashimoto and co-workers in 1996 for the Prussian blue analogue $\mathrm{K}_{0.2} \mathrm{Co}_{1.4}\left[\mathrm{Fe}(\mathrm{CN})_{6}\right]_{3} \cdot 6.9 \mathrm{H}_{2} \mathrm{O} .^{3}$ Since this discovery, considerable effort has been focussed on the development of new cyanide bridged heterometallic molecular materials with reversible metal-to-metal electron-transfer behaviour. ${ }^{4}$ In 2004, Dunbar et. al. reported an interesting trigonal pyramidal $\left[\mathrm{Co}_{3} \mathrm{Fe}_{2}\right]$ complex which showed a one electron transfer process for the two ETCST-active [CoFe] pairs in the molecule with electronic states

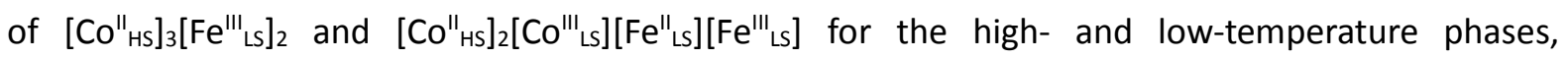
respectively. ${ }^{5}$ The ETCST behaviour of this material was found to be strongly related to the degree of solvation in the crystal lattice: desolvation led to a red solid locked in the $\left[\mathrm{CO}^{\prime \prime} \mathrm{HS}_{3}\left[\mathrm{Fe}^{\mathrm{III}} \mathrm{LS}_{2}\right]_{2}\right.$ state across the whole temperature range, and the further re- absorption of water resulted in a blue solid in the

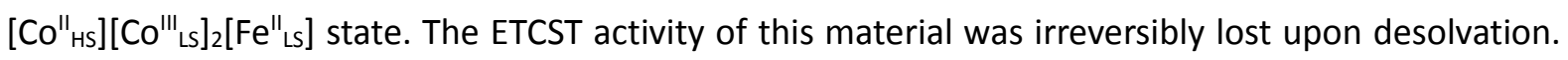
The group found that the $\left[\mathrm{M}_{3} \mathrm{M}_{2}^{\prime}\right]$ molecular architecture could be extended to over twenty complexes 
using the same capping ligand, ${ }^{6}$ and found that the [FeOs] homologue also exhibited ETCST behaviour. ${ }^{6 e}$

Over the course of our study of cyanide-bridged systems, ${ }^{7}$ we have noted that structural perturbations arising from the desorption or absorption of solvent molecules can drastically affect the electron transfer processes of [CoFe] complexes, offering a convenient means to fine-tune the redox potential of [CoFe] pairs and thus control the ETCST in the solid state. However, as highlighted above, modification of ETCST behaviour upon guest desorption/absorption is usually irreversible due to the possibility of structural collapse during the rearrangement of the molecules. ${ }^{8}$

Herein, we report a cyanide-bridged trigonal bipyramidal pentanuclear complex $\left(\mathrm{Et}_{4} \mathrm{~N}\right)\left[\left\{\mathrm{Co}(\mathrm{L})_{2}\right\}_{3}\left\{\mathrm{Fe}(\mathrm{CN})_{6}\right\}_{2}\right]\left(\mathrm{ClO}_{4}\right) \cdot 13 \mathrm{EtOH}(\mathbf{1})$ (L = N-(2-pyridylmethylene-(S)-(+)-1,2,3,4-tetrahydro-1-

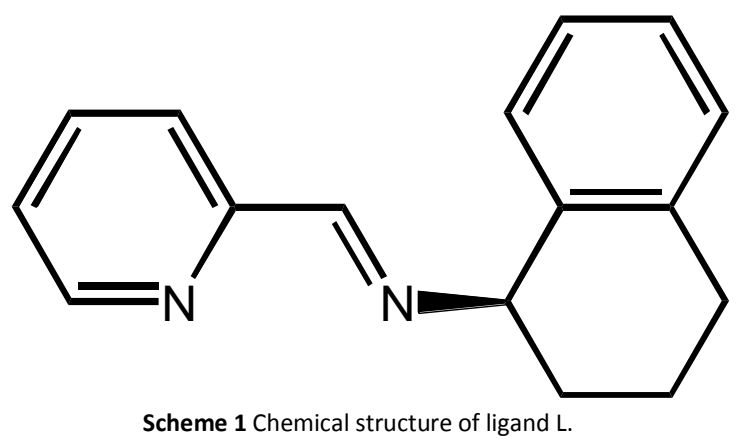

naphthylamine, Scheme 1). The complex exhibits thermally induced complete ETCST behaviour that can be switched 'off' and 'on' by reversible solvent desorption and re-absorption.

The pentanuclear complex 1 was obtained as red needle crystals by the reaction of $\mathrm{CoCl}_{2} \cdot 6 \mathrm{H}_{2} \mathrm{O}$, 2pyridinecarbaldehyde, $(S)-(+)-1,2,3,4$-Tetrahydro-1-naphthylamine, $\left(\mathrm{Et}_{4} \mathrm{~N}\right)_{3}\left[\mathrm{Fe}(\mathrm{CN})_{6}\right]$ and $\left(\mathrm{Et}_{4} \mathrm{~N}\right) \mathrm{ClO}_{4}$ in an ethanolic solution. X-ray structural data were collected at 100 and $300 \mathrm{~K}$ of 1 and the structure analyses reveal the heterometallic $\left[\mathrm{CO}_{3} \mathrm{Fe}_{2}\right]$ complex to crystallise in the orthorhombic space group $P 2_{1} 2_{1} 2_{1}$ with a neutral cyanide-bridged trigonal bipyramidal structure comprising three $\left[\mathrm{Co}\left(\mathrm{L}_{2}\right]^{2+}\right.$ moieties in the equatorial plane with two $\left[\mathrm{Fe}(\mathrm{CN})_{6}\right]^{3-}$ moieties occupying the apical positions (Fig. 1). $\neq$ Each $\mathrm{Co}$ ion has a distorted $\mathrm{CoN}_{6}$ octahedral coordination environment, formed by four $\mathrm{N}$ atoms provided by two L groups and two from cis-coordinating cyanide groups. Each Fe centre is coordinated by six carbon atoms from cyanide groups, where three act as bridging ligands to the Co ions and the remainder act as terminal cyanide groups and show hydrogen bonding interactions to lattice EtOH molecules (Fig. S2, ESI†).

Significant structural changes associated with the intramolecular electron transfer process can also be observed with changing temperature. At $100 \mathrm{~K}$, the $\mathrm{Co}-\mathrm{N}$ bond lengths for $\mathrm{Co} 1$ and $\mathrm{Co} 2$ ranged from $1.873(9)$ to $1.963(9) \AA$, in accordance with typical Co"'Is-N bond lengths (ca. $1.9 \AA \AA^{5,7 b}$. In contrast, Co3 


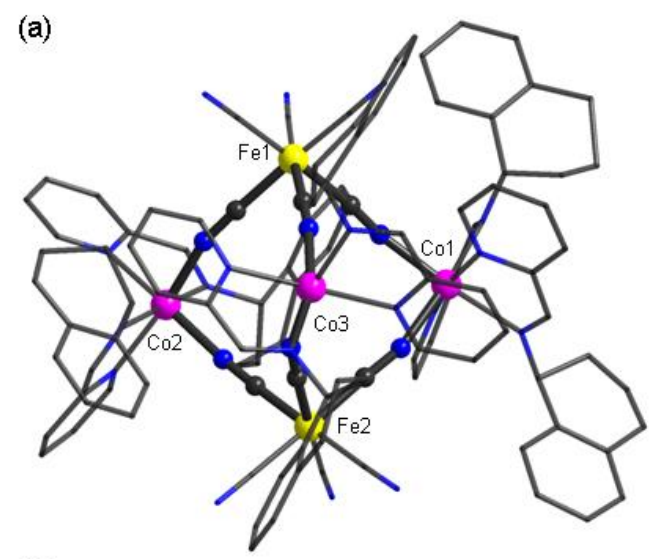

(b)

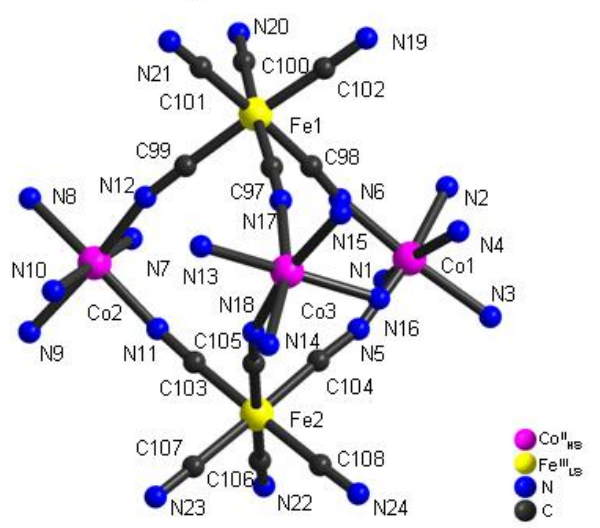

Fig. 1 Molecular (a) and core (b) structures of 1 at $300 \mathrm{~K}$. The hydrogen atoms, $\left(\mathrm{Et}_{4} \mathrm{~N}\right)^{+}, \mathrm{ClO}_{4}{ }^{-}$, and solvent molecules have been omitted for clarity.

was assigned to a $\mathrm{CO}^{\prime \prime}{ }_{\mathrm{HS}}$ state based on the significantly longer Co-N bond lengths of $2.027(8)$ to $2.201(8) \AA$ (expected value for $\mathrm{CO}^{\prime \prime}{ }_{\mathrm{HS}}=2.1 \AA$ ) ${ }^{5,7 \mathrm{~b}}$. It is challenging to elucidate the difference between $\mathrm{Fe}^{\prime \prime}$ LS and $\mathrm{Fe}^{\prime \prime \prime \prime}$ เS states with X-ray analysis alone, however, the electronic state of all Fe ions was found to be Fe" ${ }_{\mathrm{LS}}$ at $100 \mathrm{~K}$ by Mössbauer spectra (see below), giving a composition of [ $\left.\mathrm{CO}^{\prime \prime} \mathrm{HS}\right]\left[\mathrm{CO}^{\prime \prime \prime}{ }_{\mathrm{LS}}\right]_{2}\left[\mathrm{Fe}_{\mathrm{LS}}\right]_{2}$ in the low-temperature (LT) phase. As the temperature was increased to $300 \mathrm{~K}$, the average Co- $\mathrm{N}$ distances for the Co1 and Co2 ions showed a significant increase from 1.924 to $2.135 \AA$ and from 1.928 to $2.101 \AA$, respectively, whereas the value associated with Co3 remained virtually constant. The changes in the Co1-N and Co2-N bond lengths (c.a. $0.2 \AA$ ) suggest electron transfer occurs at the Co1 and $\mathrm{Co} 2$ centres upon temperature increase. Mössbauer spectroscopic analysis indicates that the Fe ions are oxidized to the $\mathrm{Fe}^{\mathrm{III}} \mathrm{LS}$ state at $300 \mathrm{~K}$ during the electron transfer process, leading to a $\left[\mathrm{CO}^{\prime \prime} \mathrm{HS}_{3}\left[\mathrm{Fe}^{\mathrm{III}} \mathrm{LS}_{2}\right.\right.$ high-temperature (HT) phase.

The magnetic susceptibility of 1 was measured in the temperature range of $300-2 \mathrm{~K}$ to elucidate the ETCST behaviour and the resulting $\chi_{M} T$ versus $T$ plots are depicted in Fig. 2 . The $\chi_{M} T$ value at $300 \mathrm{~K}$ is $9.92 \mathrm{emu} \mathrm{mol}^{-1} \mathrm{~K}$, which is in good agreement with the assignment of three Co" $\mathrm{HS}$ and two $\mathrm{Fe}^{\prime \prime \prime}$ LS ions (assuming $S=3 / 2, g=2.5$ for $\mathrm{CO}^{\prime \prime}{ }_{\mathrm{HS}}$ and $S=1 / 2, g=2.3$ for Fe $\left.{ }^{\mathrm{III}}{ }^{7}\right)^{7 \mathrm{~g}}$ predicted by crystallographic studies and ${ }^{57} \mathrm{Fe}$ Mössbauer analysis. Upon lowering the temperature, the $\chi_{M} T$ value initially remains constant and then decreases abruptly to reach a value of $3.02 \mathrm{emu} \mathrm{mol}^{-1} \mathrm{~K}$ at $224 \mathrm{~K}$, a value close to that 
expected for a single Co"HS ion. The further decrease of the $\chi_{M} T$ value below $100 \mathrm{~K}$ is due to the orbital contribution of the remaining $\mathrm{CO}^{\prime \prime} \mathrm{HS}$ ion. Upon heating, the $\chi_{\mathrm{M}} T$ values increase, ultimately returning to the initial value, giving a plot that closely tracks that collected in cooling mode. A fully reversible, thermally induced [ $\mathrm{CO}^{\prime \prime} \mathrm{HS}_{3}\left[\mathrm{Fe}^{\prime \prime \prime}{ }_{\mathrm{Ls}}\right]_{2} \leftrightarrow\left[\mathrm{CO}^{\prime \prime} \mathrm{HS}_{3}\right]\left[\mathrm{CO}{ }^{\prime \prime \prime}{ }_{\mathrm{LS}}\right]_{2}\left[\mathrm{Fe}_{\mathrm{Ls}}\right]_{2}$ transition with $T_{1 / 2}$ of $262 \mathrm{~K}$ is thus inferred.

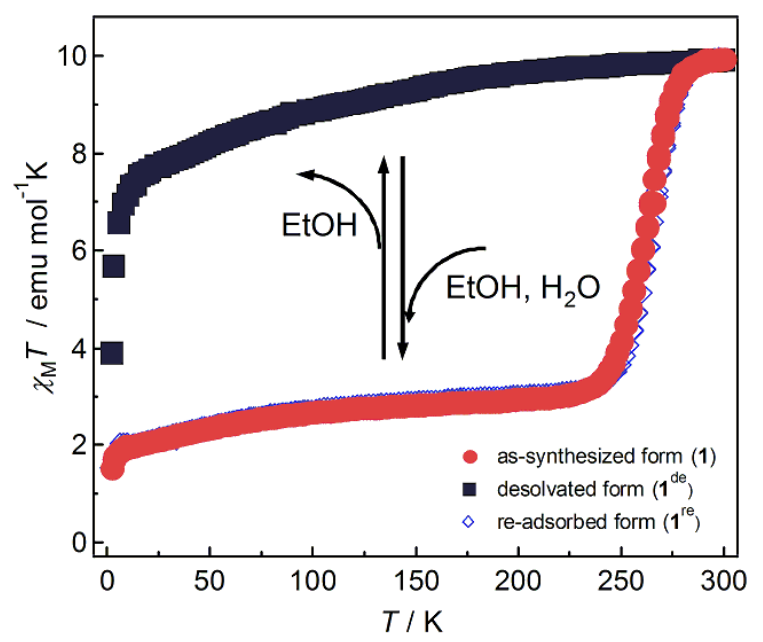

Fig. $2 \chi_{M} T$ versus $T$ plots for the $\left[\mathrm{CO}_{3} \mathrm{Fe}_{2}\right]$ complex in different solvated forms.

${ }^{57} \mathrm{Fe}$ Mössbauer spectra were also collected at various temperatures to determine the oxidation and spin states of the Fe centers. The sample was suspended in EtOH to prevent possible lattice solvent loss during measurement. The spectra are depicted in Fig. 3 and the Mössbauer parameters are summarized in Table S3, ESIt. The Mössbauer spectrum collected at $100 \mathrm{~K}$ showed one quadrupole doublet characteristic of Fe" LS species $^{5 \mathrm{a}}$ with an isomer shift of $\delta_{\mathrm{IS}}=0.00$ and quadrupole splitting of $\Delta E_{\mathrm{Q}}=0.20 \mathrm{~mm} \mathrm{~s}^{-1}$, relative to $\alpha$-Fe foil at room temperature. The values were consistent with the $[\mathrm{CO} " \mathrm{HS}]\left[\mathrm{CO} "{ }^{\prime \prime}{ }_{\mathrm{L}}\right]_{2}\left[\mathrm{Fe}_{\mathrm{LS}} \mathrm{LS}_{2}\right.$ assignment obtained from the crystallographic studies and the magnetic data. As the temperature was increased to $260 \mathrm{~K}$, an additional doublet corresponding to $\mathrm{Fe}^{\mathrm{III}} \mathrm{LS}^{6 \mathrm{~g}}$ was observed with Mössbauer parameters of $\delta_{\mathrm{IS}}=-0.07$ and $\Delta E_{\mathrm{Q}}=0.56 \mathrm{~mm} \mathrm{~s}^{-1}$, suggesting thermally induced electron transfer had occurred between the neighbouring metal centres. The area fractions of the $\mathrm{Fe}^{\prime \prime \prime \prime}\left\llcorner\right.$ and $\mathrm{Fe}^{\prime \prime}$ เS components at $260 \mathrm{~K}$ were $45 \%$ and $55 \%$, respectively, in agreement with the $\mathrm{Fe}^{\prime \prime \prime}$ เS/Fe" $\mathrm{LS}$ ratio (0.44/0.56) calculated from the magnetic data at the same temperature, indicating

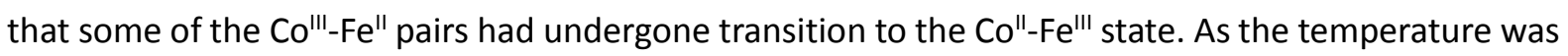
further increased to $300 \mathrm{~K}$, the Fe"'ıs fraction reached a value of $100 \%$, suggesting full ETCST from the LT to HT phase. 
Upon drying under $\mathrm{N}_{2}$, complex 1 undergoes a single-crystal to single-crystal (SC-SC) transformation whereby the solvent molecules in the crystal lattice are partially lost to give a desolvated form with a formula of $\left(\mathrm{Et}_{4} \mathrm{~N}\right)\left[\left\{\mathrm{Co}(\mathrm{L})_{2}\right\}_{3}\left\{\mathrm{Fe}(\mathrm{CN})_{6}\right\}_{2}\right]\left(\mathrm{ClO}_{4}\right) \cdot 5 \mathrm{EtOH}\left(\mathbf{1}^{\mathrm{de}}\right)$. X-ray diffraction data collected at $100 \mathrm{~K}$ reveals that the desolvated complex $\mathbf{1}^{\text {de }}$ retained in the same $P 2{ }_{1} 2_{1} 2_{1}$ system and with similar $a$ and $b$ cell lengths to $\mathbf{1}$, but with a significantly shorter $c$ axis (46.041(3) and 38.04(2) $\AA$ for $\mathbf{1}$ and $\mathbf{1}^{\text {de }}$, respectively), resulting in a unit cell volume reduction of c.a. $17 \%$.‡ Further analysis shows that the average Co-N bond lengths for the three Co" centers range from 2.095 to $2.150 \AA$, indicative of Co"Hs ions.

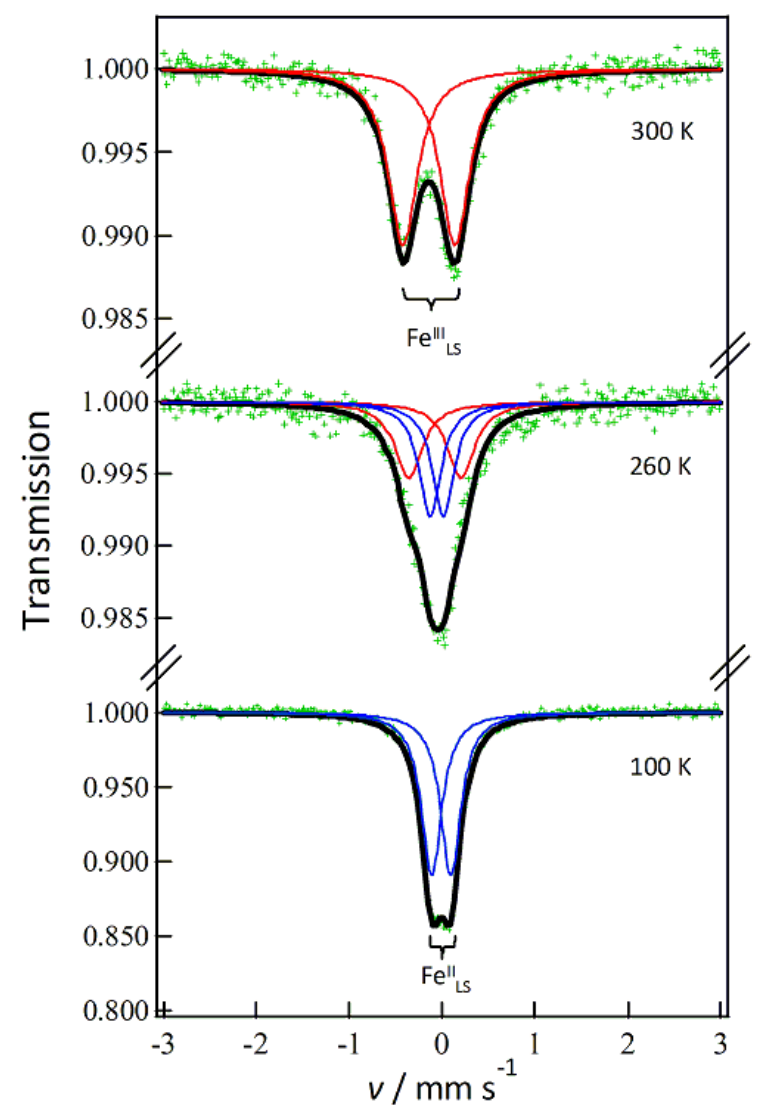

Fig. 3 Mössbauer spectra of as-synthesized 1 at various temperatures. The green crosses are the experimentally obtained data points and the solid lines are the Lorentzian curves calculated using the parameters given in Table S3, ESIt.

Meanwhile, the Mössbauer spectrum collected at $100 \mathrm{~K}$ for $\mathbf{1}^{\text {de }}$ suggests that all Fe ions are in their Fe ${ }^{\prime \prime \prime}$ LS states (Fig. S7, ESIT). In other words, the desolvated form $\mathbf{1}^{\text {de }}$ maintains the same electronic structure $\left(\left[\mathrm{CO}^{\prime \prime}{ }_{\mathrm{HS}}\right]_{3}\left[\mathrm{Fe}^{\mathrm{III}}{ }_{\mathrm{LS}}\right]_{2}\right)$ as the $\mathrm{HT}$ phase of 1 , even at $100 \mathrm{~K}$ and no electron transfer occurs upon temperature change. The absence of ETCST is further confirmed by magnetic measurement (Fig. 2). The notable difference in the ETCST activity for the fresh and desolvated forms is most likely derived from the change of hydrogen bonding interactions during the desolvation process.

Complex 1 shows various hydrogen bonding interactions between terminal cyanide groups of the $\left[\mathrm{CO}_{3} \mathrm{Fe}_{2}\right]$ cluster and EtOH solvent molecules, which stabilize the hexacyanoferrate units in the electron-rich $\mathrm{Fe}^{\mathrm{ll}}$ state by exerting an electron-withdrawing effect. ${ }^{7 \mathrm{~g}}$ The loss of solvent leads to the destabilization of the $\left[\mathrm{CO}^{\prime \prime} \mathrm{HS}\right]\left[\mathrm{CO}{ }^{\prime \prime \prime}{ }_{\mathrm{LS}}\right]_{2}\left[\mathrm{Fe}{ }^{\prime \prime}{ }_{\mathrm{LS}}\right]_{2} \mathrm{LT}$ phase and thus the absence of ETCST. Interestingly, when 
the desolvated complex $\mathbf{1}^{\text {de }}$ was exposed to ethanol vapour, the magnetic behaviour of the reabsorbed sample $\left(\left(\mathrm{Et}_{4} \mathrm{~N}\right)\left[\left\{\mathrm{Co}(\mathrm{L})_{2}\right\}_{3}\left\{\mathrm{Fe}(\mathrm{CN})_{6}\right\}_{2}\right]\left(\mathrm{ClO}_{4}\right) \cdot 7 \mathrm{EtOH} \cdot 7 \mathrm{H}_{2} \mathrm{O}, \mathbf{1}^{\text {re }}\right)$ was effectively restored to that of the as-synthesized sample, showing only a slight increase of $T_{1 / 2}$ to $265 \mathrm{~K}$. The structure of the reabsorbed form $\mathbf{1}^{\text {re }}$ is consistent with that of the fresh $\mathbf{1}$, as evidenced by Synchrotron powder XRD studies (Fig. S10, ESI + ). The results suggest that the $\left[\mathrm{CO}_{3} \mathrm{Fe}_{2}\right]$ cluster in $\mathbf{1}$ is stable during solvent desorption/adsorption and shows significant solvent-tunable ETCST behaviour.

In conclusion, we have reported a pentanuclear trigonal bipyramidal $\left[\mathrm{CO}_{3} \mathrm{Fe}_{2}\right]$ cluster that exhibits thermal ETCST activity and is uniquely sensitive to the degree of solvation. This has allowed us to demonstrate a solvent-driven fully reversible on/off switching mechanism. The present complex therefore constitutes a rare example of the control of magnetic bi-stability through dynamic host-guest interactions in the solid state. Studies on the selective guest dependence of the ETCST behaviour are currently ongoing and will be reported in due course.

This work was supported by a Grant-in-Aid scientific research (no. 25248014) from the Japan Society for the Promotion of Science (JSPS) and by a research grant (2016G175) from KEK. R.-J. W. and J. M. C. thank JSPS for postdoctoral fellowships.

\section{Notes and references}

¥X-ray crystallographic data for $1: \mathrm{C}_{142} \mathrm{H}_{194} \mathrm{ClCO}_{3} \mathrm{Fe}_{2} \mathrm{~N}_{25} \mathrm{O}_{17}, M_{\mathrm{r}}=2847.15 \mathrm{~g} \mathrm{~mol}^{-1}$, Orthorhombic, $P 2{ }_{1} 2_{1} 2_{1}, Z=4, T=100 \mathrm{~K}, a=16.6410(11) \AA, b=18.9061$ (13) $\AA, c=46.041(3) \AA, V=14485.2(17)$ $\AA^{3}, D_{\mathrm{c}}=1.306 \mathrm{~g} \mathrm{~cm}^{-3}, \mu($ Mo $K \alpha)=0.621 \mathrm{~mm}^{-1} ; 154669$ data measured, 28547 unique $\left(R_{\text {int }}=\right.$ 0.1117), 1608 parameters, $R_{1}=0.0803$ (20854 with $\left.I>2 \mathrm{~s}(I)\right), w R_{2}=0.2156$ (all data), $\mathrm{S}=1.056$, Flack parameter $=0.030(18) \cdot T=300 \mathrm{~K}, a=17.278(2) \AA, b=18.940(2) \AA, c=48.462(6) \AA, V=$ $15859(3) \AA^{3}, D_{\mathrm{c}}=1.192 \mathrm{~g} \mathrm{~cm}^{-3}, \mu($ Mo $K \alpha)=0.567 \mathrm{~mm}^{-1} ; 84465$ data measured, 31152 unique $\left(R_{\text {int }}\right.$ $=0.1012$ ), 1042 parameters, $R_{1}=0.0741$ (10348 with $\left.I>2 \mathrm{~s}(I)\right), w R_{2}=0.1579$ (all data), $\mathrm{S}=1.033$, Flack parameter $=0.028(16)$.

X-ray crystallographic data for $1^{\text {de }}: \mathrm{C}_{126} \mathrm{H}_{145} \mathrm{ClCO}_{3} \mathrm{Fe}_{2} \mathrm{~N}_{25} \mathrm{O}_{9}, M_{\mathrm{r}}=2477.61 \mathrm{~g} \mathrm{~mol}^{-1}$, Orthorhombic, $P 2{ }_{1}{ }_{1} 2_{1}, \mathrm{Z}=4, T=100 \mathrm{~K}, a=16.991(9) \AA, b=18.555(10) \AA, c=38.04(2) \AA, V=11993(11) \AA^{3}, D_{c}=1.372$ $\mathrm{g} \mathrm{cm}^{-3}, \mu($ Mo $K \alpha)=0.734 \mathrm{~mm}^{-1} ; 111656$ data measured, 21113 unique $\left(R_{\text {int }}=0.1613\right), 1608$ parameters, $R_{1}=0.1655(13143$ with $I>2 \mathrm{~s}(I)), w R_{2}=0.4256$ (all data), $\mathrm{S}=1.013$, Flack parameter $=$ 0.24(5). The intensity data were collected on a Bruker SMART APEX II diffractometer with Mo-K $\alpha$ radiation ( $\lambda=0.71073 \AA$ ) . Empirical absorption corrections by SADABS (G. M. Sheldrick, 1994) were applied to the reflection data. Direct methods were used to solve the structure and to locate the heavy 
atoms using the SHELXTL-97 program package. The remaining atoms were found from successive fullmatrix least-squares refinements on $F^{2}$ and Fourier syntheses.

1 (a) G. N. Newton, M. Nihei and H. Oshio, Eur. J. Inorg. Chem., 2011, 2011, 3031; (b) D. Aguilà, Y. Prado, E. S. Koumousi, C. Mathonière and R. Clérac, Chem. Soc. Rev., 2016, 45, 203.

2 O. Sato, J. Tao and Y. Z. Zhang, Angew. Chem. Int. Ed., 2007, 46, 2152.

3 O. Sato, T. Iyoda, A. Fujishima and K. Hashimoto, Science, 1996, 272, 704.

4 (a) D. Li, R. Clérac, O. Roubeau, E. Harté, C. Mathonière, R. Le Bris and S. M. Holmes, J. Am. Chem. Soc., 2008, 130, 252; (b) T. Liu, Y. J. Zhang, S. Kanegawa and O. Sato, Angew. Chem. Int. Ed., 2010, 49, 8645; (c) Y. Zhang, D. Li, R. Clérac, M. Kalisz, C. Mathonière and S. M. Holmes, Angew. Chem. Int. Ed., 2010, 49, 3732; (d) D. P. Dong, T. Liu, S. Kanegawa, S. Kang, O. Sato, C. He and C. Y. Duan, Angew. Chem. Int. Ed., 2012, 51, 5119; (e) E. S. Koumousi, I.-R. Jeon, Q. Gao, P. Dechambenoit, D. N. Woodruff, P. Merzeau, L. Buisson, X. Jia, D. Li, F. Volatron, C. Mathonière and R. Clérac, J. Am. Chem. Soc., 2014, 136, 15461.

5 (a) C. P. Berlinguette, A. Dragulescu-Andrasi, A. Sieber, J. R. Galán-Mascarós, H.-U. Güdel, C. Achim and K. R. Dunbar, J. Am. Chem. Soc., 2004, 126, 6222; (b) C. P. Berlinguette, A. Dragulescu-Andrasi, A. Sieber, H.-U. Güdel, C. Achim and K. R. Dunbar, J. Am. Chem. Soc., 2005, 127, 6766.

6 (a) C. P. Berlinguette, D. Vaughn, C. Cañada-Vilalta, J. R. Galán-Mascarós and K. R. Dunbar, Angew. Chem. Int. Ed., 2003, 42, 1523; (b) M. Shatruk, K. E. Chambers, A. V. Prosvirin and K. R. Dunbar, Inorg. Chem., 2007, 46, 5155; (c) M. G. Hilfiger, M. Shatruk, A. Prosvirin and K. R. Dunbar, Chem. Commun., 2008, 5752; (d) K. E. Funck, M. G. Hilfiger, C. P. Berlinguette, M. Shatruk, W. Wernsdorfer and K. R. Dunbar, Inorg. Chem., 2009, 48, 3438; (e) M. G. Hilfiger, M. Chen, T. V. Brinzari, T. M. Nocera, M. Shatruk, D. T. Petasis, J. L. Musfeldt, C. Achim and K. R. Dunbar, Angew. Chem. Int. Ed., 2010, 49, 1410; (f) X.-Y. Wang, M. G. Hilfiger, A. Prosvirin and K. R. Dunbar, Chem. Commun., 2010, 46, 4484; (g) M. Shatruk, A. Dragulescu-Andrasi, K. E. Chambers, S. A. Stoian, E. L. Bominaar, C. Achim and K. R. Dunbar, J. Am. Chem. Soc., 2007, 129, 6104.

7 (a) K. Mitsumoto, E. Oshiro, H. Nishikawa, T. Shiga, Y. Yamamura, K. Saito and H. Oshio, Chem. - Eur. J., 2011, 17, 9612; (b) M. Nihei, Y. Sekine, N. Suganami, K. Nakazawa, A. Nakao, H. Nakao, Y. Murakami and H. Oshio, J. Am. Chem. Soc., 2011, 133, 3592; (c) N. Hoshino, F. lijima, G. N. Newton, N. Yoshida, T. Shiga, H. Nojiri, A. Nakao, R. Kumai, Y. Murakami and H. Oshio, Nat. Chem., 2012, 4, 921; (d) M. Nihei, Y. Okamoto, Y. Sekine, N. Hoshino, T. Shiga, I. P. C. Liu and H. Oshio, Angew. Chem. Int. Ed., 2012, 51, 6361; (e) G. N. Newton, K. Mitsumoto, R.-J. Wei, F. lijima, T. Shiga, H. Nishikawa and H. Oshio, Angew. Chem. Int. Ed., 2014, 53, 2941; (f) Y. Sekine, M. Nihei, R. Kumai, H. Nakao, Y. Murakami and H. Oshio, Chem. Commun., 2014, 50, 4050; (g) T. Shiga, T. Tetsuka, K. Sakai, Y. Sekine, M. Nihei, G. N. Newton and H. Oshio, Inorg. Chem., 2014, 53, 5899.

8 (a) M. Nihei, L. Han and H. Oshio, J. Am. Chem. Soc., 2007, 129, 5312; (b) L. Cao, J. Tao, Q. Gao, T. Liu, Z. Xia and D. Li, Chem. Commun., 2014, 50, 1665; (c) C. Zheng, J. Xu, Z. Yang, J. Tao and D. Li, Inorg. Chem., 2015, 54, 9687. 